\title{
Global Aspects of Social Media Perception by $Y$ Generation in Gender Context
}

\author{
Lucja Matusiková1,*, Kateřina Stanovská2 \\ ${ }^{1}$ VŠB - Technical University, Faculty of Economic, 70200 Ostrava 1, Sokolská třída 33, Czech \\ Republic \\ ${ }^{2}$ VŠB - Technical University, Faculty of Economic, 70200 Ostrava 1, Sokolská třída 33, Czech \\ Republic
}

\begin{abstract}
Influencers, You tubers, opinion leaders, social network, social media, message, hashtag, share. These words are around us. We have become international, now we are a global country that cannot influence many aspects. The present generation cannot imagine life without social networks. The research focus on intergenerational comparison of the perception of social networks. We aim our attention at gender factor in $\mathrm{Y}$ generation. Generation Y, is the demographic group following Generation $\mathrm{X}$. This generation as known as internet generation (iGen), Net generation or Generation 9/11. Generations Y are mostly baby boomers, children born in post-war years. It is generation who have used Information and Communication Technologies (ICT) since childhood. The aim of submitted paper is found out answers to two questions and confirm or reject the hypotheses. Two questions are how long have respondents spent time on the Internet? And what they use social networks? We have set a null hypothesis and its alternative. Null hypothesis is gender factor affects the perception of social networks. Alternative hypothesis is Gender factor does not affect the perception of social networks. We used to confirm or reject the hypothesis Chi - Square test via MS Excel. We expect gender factor affects the social networks.
\end{abstract}

\section{Introduction}

In recent decades, globalisation has struck with unprecedented power. The world has shrunk. Information from anywhere on Earth comes to us in the blink of an eye via TV and the Internet. Population migration across countries and continents is intensifying. The goods we buy come from different parts of the world. People living in different communities and societies wear similar, fashionable clothes, listen to the music of the same artists. And there are social media coming into this. Terms such as Facebook, YouTube and others are increasingly mentioned not only by the marketing and PR staff. Generation Y, people born approximately between 1976 and 2005, has entered the active work environment. It is a social cohort that has been brought up with social networks. And it becomes clear that if we want

\footnotetext{
*Corresponding author: Lucja.matusikova@vsb.cz
} 
to engage Gen Y more actively in social and working life, we need to take into account their communication channels. The media, and the social media mentioned above, are one of the ways to address this generation. This topic is devoted to a number of publications [1-5].

The aim of submitted paper is found out answers to two questions and confirm or reject the hypotheses. Two questions are how long have respondents spent time on the Internet? And what they use social networks? We have set a null hypothesis and its alternative. Null hypothesis is gender factor affects the perception of social networks. Alternative hypothesis is Gender factor does not affect the perception of social networks. We used to confirm or reject the hypothesis Chi - Square test via SPPS program. We expect gender factor affects the social networks.

\section{Definition of Basic Terms and Testing Hypothesis}

For the purposes of a correct interpretation of achieved results, we need to approach at least in basic dimensions the main notions that we will subsequently work with. Only the facts that are essential and more closely specifying or explaining individual concepts will be included.

\subsection{Media}

The Dictionary of Foreign Words defines the notion Medium as a mediation agent, environment, also as person arranging information and, finally, as mass media printed (for example: newspapers, magazines) as well as electronic (radio, television and internet), mass medium. The word medium is similarly characterized also by other authors, who state that it is of the Latin origin and means a mediator, intermediating agent, that is anything that mediates. The medium is presented here as a direct individual means of communication as well as labelling a technical means of communication. On the one hand, we encounter such characteristics as facial expressions, gestures or speech and, on the other hand, the computer network, cable television, etc. Mass media means of communication and institutions that are able to produce in the large scale public notification and distribute it towards the scattered, varied and individually unnamed public.

\subsection{Social media}

Definitions imply that social media are media that allow readers to react, edit, comment and otherwise become involved in the text or content of the media immediately. So social media are up-to-date, offer bulk content editing (readers interact with each other's opinions), are socially validated and share content [6]. According [7] social media can be defined as a group of web-based application solutions that build on the ideological and technological basis of Web 2.0 and that allow the creation and exchange of user-generated content. According to the same authors, six types of social media can be distinguished: collaborative project (e.g. Wikipedia), blogs and microblogs, content communities, social networks, virtual game and virtual social world.

\subsection{Generation}

The notion "generation" has several meanings. The generation is characterized first, that is a set of people born and living approximately at the same time. A generation sometimes means descendants of one pair of parents. According to the Australian study of the labour market from 2007, currently, we may specify the following generationally differentiated groups of population:
- $\quad$ Born before 1946
$=$
Pre Boomers 
- $\quad$ Born from 1947 to1960

- $\quad$ Born from 1961 to1975

- Born between 1976 and 1990

- Born between 1995 and 2020

$\begin{array}{ll}= & \text { Baby Boomers } \\ = & \text { Generation X } \\ = & \text { Generation Y } \\ = & \text { Generation Z }\end{array}$

For the purposes of presenting the results of the present research, only one generation is specified in detail, that is Generation Y.

Australian survey classifies Generation Y as those born between 1976-1990. According to the survey held by Deloitte Czech, Generation $\mathrm{Y}$ is supposed to have been born between 1982-1993. Also other experts are quite doubtful about drawing an exact line between generations as various segments mingle and individual features must be taken into consideration. For this reason, we can find the following time intervals to which members of Generation Y are assigned: 1977-1995 [8]; 1980-1995 [9]; 1981-1999 [10]; 1982-1994 [11]; 1982-2000 [12]; 1982-2001 [13]; 1982-2002 [14]; 1982-2005 [15].

How is a basic characteristics of $\mathrm{Y}$ generation?

- As for information technology, they are light years ahead their colleagues;

- They are not afraid of studying two and more universities at the same time, especially when they do not know which line of business to take;

- Apparently, they are not against formalised education, but they see the reason to gain experience and practical verification of theory learned at school;

- Change stands as a life motto for them, not at all as an obstacle, as they do not need security in their lives;

- To gain new experience and stimuli, they are well ready to travel round the world if they see some sense in it;

- Working with just one company all their life long as their parents did is a meaningless concept;

- Their decisions are practical and pragmatic;

- They focus on price and compensate a lack of quality in such a manner;

- They tend to stay in a family nest as it provides comfort.

\subsection{Testing hypothesis}

At this point it should be emphasized [16 - 18] that in terms of practical application of statistical methods in analysing empirical data, statistical hypothesis testing represents one of the most important parts of all. One of the basic statistic methods for the assessment of set hypotheses, is the Chi-square test of independence. The test is most often performed in MS Excel via the statistical function CHITEST.

The role of hypothesis testing is to decide about the basis of information obtained from random samples, whether we accept or reject a particular hypothesis concerning the master sample. The statistical hypothesis [19] can be understood as any statement that may involve unknown parameters, set functions of the parameters, but also the shape of the distributions and other characteristics of the master sample. A decision rule by which we assign a decision on the validity or invalidity of the hypothesis is called a statistical test.

The first step in statistical testing is always a statistical hypothesis formulation, i.e. a formulation of a research question in the experiment in the form of a zero and alternative statistical hypothesis, which are asked when testing against each other.

The second step in testing statistical hypotheses consists in determining a significance level of the test (error $\alpha$ selected by an expert), which is the probability that the null hypothesis will be rejected, although it is valid. We should be aware of the fact that the tested hypothesis is always accepted or rejected based on the results of the random selection and therefore, the rejection as well as the non-rejection of the $H_{0}$ hypothesis can be correct, but also incorrect. As Table 1 shows, in general, we can commit one of two errors. 
Table 1. Error of type I and II

\begin{tabular}{|c|c|c|}
\hline Test conclusion & $\begin{array}{c}\text { Reality } \\
\text { H0 is applicable }\end{array}$ & $\begin{array}{c}\text { Reality } \\
\text { H0 is not applicable }\end{array}$ \\
\hline$H_{0}$ will be accepted & Correct decision & Error of type II \\
\hline$H_{0}$ will be rejected & Error of type I & Correct decision \\
\hline
\end{tabular}

The error of type I means the probability that the valid null hypothesis will be rejected, whereas the null hypothesis indicates that the model is accurate. The error of type II expresses the probability that the invalid null hypothesis will be accepted, which means that the inaccurate model will be accepted as accurate. There is an opposite relation between the error of type I and II. If the error of type I is minimized, the error of type II increases and vice versa. It should be noted that the adoption of the inaccurate model, the error of type II, is much worse than the rejection of the accurate model, the error of type I, it is better to be exposed to a higher error of the type I, thereby the error of type II will decrease.

The formulation of the test conclusion is the last step in statistical hypotheses testing, which is determined in dependence on the selected significance level $\alpha$. The $p$-value is used in statistical testing of the suitability of the model using different software. The $p$-value expresses the probability of rejecting the true null hypothesis and the error of type I. If $p$ value is less than the significance level $\alpha$ ( $\alpha$ error), the null hypothesis $\mathrm{H}_{0}$ will be rejected. Symbolically, a conclusion can be used: $p<0.05$ statistically significant difference, $p<$ 0.01 statistically highly significant difference.

\section{Results of the research}

The optimal sample for most research is obviously the one that best fits the target group, i.e. it also takes into account other criteria such as gender structure, education, residence, etc. The only limiting factor was age. The tools used to collect the data were a face-to-face questionnaire survey and a tailor-made questionnaire through the Internet portal www.click4survey.cz. The survey, which took place at the turn of May and June 2019, was attended by 303 respondents, including 174 women and 129 men of the relevant age category. In this connection the following hypotheses were determined:

$H_{0}$ : Within the particular sample, the respondents' gender does not have impact on their responses. sample.

$H_{l}$ : The respondents' gender have impact on their responses within the particular

The Chi-square test of independence in the contingency table will be used to confirm or reject the established hypotheses. The test was carried out in MS Excel via the statistical function CHITEST. Significance level is $5 \%$.

\subsection{Results and Conclusions of Social Media Perception by Y Generation in Gender Context}

First, the respondents were supposed to answer the question of how much time they spend on the Internet every day. The results are given in Table 2.

It is apparent that $31 \%$ of women surveyed and $7 \%$ of men surveyed spend about an hour a day on the Internet. For two hours, the results are already $17 \% / 24 \%$ in favour of men. Men hold the majority for other time figures too, namely $16 \% / 14 \%$ for up to three hours and relatively significant $53 \%$ / $38 \%$ for more than three hours a day spent on the Internet. The 
test showed dependence of gender factor on respondents' answers. It was also interesting to find out why they spend their time on the Internet. The results are shown in Table 3.

Table 2. How much times do you spend on the Internet in general?

\begin{tabular}{|c|c|c|c|c|}
\hline Question 1 & Till one hour & Till two hours & $\begin{array}{c}\text { Till three } \\
\text { hours }\end{array}$ & $\begin{array}{c}\text { More than three } \\
\text { hours }\end{array}$ \\
\hline Women & 54 & 30 & 24 & 66 \\
\hline Men & 9 & 30 & 21 & 69 \\
\hline p-value & \multicolumn{2}{|c|}{0,00000823} & \multicolumn{2}{|c|}{$00 \%$} \\
\hline
\end{tabular}

Table 3. Why are you spend your time on the Internet?

\begin{tabular}{|c|c|c|}
\hline Question 2 & Women & Men \\
\hline Internet is the main source of information for me & 108 & 105 \\
\hline For work / school reasons & 108 & 102 \\
\hline Education and personal development & 51 & 63 \\
\hline News and articles & 81 & 87 \\
\hline Listen to music, watch videos & 33 & 72 \\
\hline I play games on the Internet & 3 & 15 \\
\hline For online purchase & 72 & 66 \\
\hline For free time & 105 & 42 \\
\hline I visit social networks & 84 & 54 \\
\hline Communicate with friends & 96 & 57 \\
\hline p-value & \multicolumn{2}{|c}{0,000} \\
\hline
\end{tabular}

The top five reasons why respondents spend time on the Internet vary with gender, which was confirmed by the test. For both sexes, the first two places are identical (the Internet is a source of information, and it is used for work or school purposes). Women then spend their free time on the Internet, communicating with friends and being active on social networks. Men read news and articles, shop and educate themselves.

Another question focused on identifying accounts that respondents use on social networks. The results are shown in Table 4.

Table 4. Do you have and use an account on these social networks?

\begin{tabular}{|c|c|c|c|c|c|c|}
\hline \multirow{2}{*}{ Question 3 } & \multicolumn{2}{|c|}{ Yes, I use it. } & \multicolumn{2}{c|}{ Yes, but I don't use it. } & \multicolumn{2}{c|}{ I have not it. } \\
\cline { 2 - 7 } & Women & Men & Women & Men & Women & Men \\
\hline Facebook & 147 & 84 & 9 & 24 & 18 & 21 \\
\hline YouTube & 42 & 78 & 27 & 12 & 105 & 39 \\
\hline Instagram & 48 & 24 & 12 & 6 & 114 & 99 \\
\hline Twitter & 6 & 6 & 9 & 18 & 159 & 105 \\
\hline Google + & 42 & 46 & 72 & 41 & 60 & 42 \\
\hline LinkedIn & 15 & 15 & 24 & 30 & 135 & 84 \\
\hline Lidé.cz & 3 & 3 & 15 & 12 & 156 & 114 \\
\hline p-values & $0,00134 \%$ & $0,00 \%$ & $0,003075 \%$ & $0,03 \%$ & 0,00721788 & $0,72 \%$ \\
\hline
\end{tabular}

The most used social network is Facebook, both for women and men. The gender factor played a role in all the other answers. This was confirmed by the independence test. Table 5 
shows the answers to the question of how much time respondents spend on social networks. $44 \%$ of women and almost $50 \%$ of men use social networks for at least an hour a day. Interestingly, $5 \%$ of men and $7 \%$ of women spend more than three hours a day on social networks, while $26 \%$ of male respondents and $10 \%$ of female respondents do not use social networks at all.

Table 5. How much time do you spend on social networks on weekdays?

\begin{tabular}{|c|c|c|c|c|c|}
\hline $\begin{array}{c}\text { Question } \\
4\end{array}$ & $\begin{array}{c}\text { Till one } \\
\text { hour }\end{array}$ & $\begin{array}{c}\text { Till two } \\
\text { hours }\end{array}$ & $\begin{array}{c}\text { Till three } \\
\text { hours }\end{array}$ & $\begin{array}{c}\text { More than three } \\
\text { hours }\end{array}$ & $\begin{array}{c}\text { I don't use social } \\
\text { networks }\end{array}$ \\
\hline Women & 78 & 57 & 9 & 12 & 18 \\
\hline Men & 60 & 27 & 3 & 6 & 33 \\
\hline p-value & \multicolumn{2}{|c|}{0,00282812} & \multicolumn{4}{|c|}{$0,28 \%$} \\
\hline
\end{tabular}

The Chi-squared test showed dependence of responses on the gender factor. The last question focused on the reasons why respondents use social networks. The results are given in Table 6.

Table 6. Why do you spend time on social networks?

\begin{tabular}{|c|c|c|}
\hline Question 5 & Women & Men \\
\hline Social networks are the main source of information for me & 24 & 12 \\
\hline Contact and communication with friends & 144 & 75 \\
\hline Finding new friends / dating & 6 & 5 \\
\hline Fun and entertainment & 45 & 39 \\
\hline Viewing photos, watching videos & 42 & 30 \\
\hline Self-presentation & 12 & 12 \\
\hline Playing games & 6 & 7 \\
\hline p-value & 0,29192019 & $29 \%$ \\
\hline
\end{tabular}

Contact and communication with friends is the most common reason for social networking activities for both women and men. It is followed by entertainment and photo and video browsing; social networks are furthermore a source of information, and other reasons include self-presentation, making new friends and playing games. This question did not show the effect of gender factor on respondents' answers.

\section{Conclusion}

Generation $\mathrm{Y}$ has been, and is, the subject of a number of scientific research, especially from the perspective of the consumer, i.e. the customer who completes the whole sales cycle. Recently researchers have also focused on social media. Studies have been carried out on the impact of Facebook advertising on the buying behaviour of Gen Y representatives in South Africa [20] or in the field of luxury fashion [21], brand awareness and buying motivation [22] and earlier, for example, the research on Gen Y's views on social applications in the business sphere [23] and many others. Social networking sites and their impact on education, purchasing and employment decisions have become a priority for many research projects. Although the presented research is very limited in a number of areas (region, scope, education, etc.), it can be stated that its results can be used especially in the area of predicting future development. The research has shown that Gen Y members spend a significant amount of time on the Internet and subsequently on social networks and that the gender factor has a significant impact on this. The only area that was not influenced by the gender factor was the reasons why respondents were using social networks. Based on the assumption that the most 
common reason why people are on a network is to find contact and communicate with friends, one works with a factor that could be used in the work environment. One could make use of an individual's own activity and naturally associate it with their work activity. As they communicate with friends and look for new ones, they can communicate with existing suppliers, buyers and look for new ones. Many companies have already started this journey and have their profiles on social networks. They mostly focus on the human resources area, i.e. searching for new employees through social networks. However, it can be stated that this is most likely just the beginning and that the development of supplier-buyer relations through the Internet, especially through social networks, is on the rise. However, the security of these relations is still an unresolved issue as GDPR is just the beginning.

This article was prepared as a part of the SGS project at the Faculty of Economics, VŠB-TU Ostrava, project number: SP2019/7.

This paper was supported within Operational Programme Education for Competitiveness - Project

No. CZ.1.07/2.3.00/20.0296.

\section{References}

1. G. Eyre, Back to Basics: the Role of Reading in Preparing Young People for the Information Society. Reference Services Review, 31, 219-226 (2003)

2. F. Haji Habibi, C. A. Hamilton, M. J. Valos, M. Callaghan, E-marketing Orientation and Social Media Implementation in B2B Marketing. European Business Review, 27, 638655 (2015)

3. L. Huotari, P. Ulkuniemi, S. Saraniemi, M. Malaska, Analysis of Content Creation in Social Media by B2B Companies. Journal of Business \& Industrial Marketing, 30, 761770 (2015)

4. J. Park, D. Gursoy, Generation Effects on Work Engagement Among US Hotel Employees. International Journal of Hospitality Management, 31, 1195-1202 (2012)

5. K. T. Smith, Longitudinal Study of Digital Marketing Strategies Targeting Millennials. Journal of Consumer Marketing, 29, 86-92 (2012)

6. T. Bouda, Sociální média, / Inflow.cz [online]. 2009 [cit. 12.1.2009]. Available from: http://www.inflow.cz/socialni-media Drake-Bridges E., Burgess B., Personal Preferences of Tween Shoppers. Journal of Fashion Marketing and Management: An International Journal, 14, 624-633 (2010)

7. A. M. Kaplan, M. Haenlein. Users of the world, unite! The challenges and opportunities of Social Media. Business Horizons, 53, 59-68 (2010)

8. New Strategist, The Millennials: Americans Born 1977 to 1994, New Strategist Publications, Ithaca 2004.

9. M. Bartlett, Analyst: Understanding What Shapes Generation Can Help the... Credit Union Journal, 8, 14-17 (2004)

10. R. N. Bolton, A. Parasuraman, A. Hoefnagels, N. Migchels, S. Kabadayi, T. Gruber, Y Komarova, D. Solnet, Understanding Generation Y and Their Use of Social Media: A Review and Research Agenda. Journal of Service Management, 24, 245-267 (2013)

11. Y. Kavounis, The Millennial effect. Brand Strategy, 229, 49-51 (2008)

12. M. Rich, Millennial Students and Technology Choices for Information Searching. Electronic Journal of Business Research Methods, 1, 73-76 (2008)

13. P. Paul, Getting Inside Gen Y. American Demographics, 9, 42-49 (2001)

14. S. Littman, Welcome to the new Millennials. Response Magazine, 16, 74-80 (2008) 
15. N. Howe, W. Strauss, Generations: The History of America's Future, 1584 to 2069, William Morrow \& Company, New York, 1991.

16. L. Matusiková, K. Kashi, K. Zelinková, Intergeneration Comparison of Experiences in Product Complaints. In: Economics and Business Management in the 21st Century. VŠB- Technical University of Ostrava, Ostrava 2016.

17. H. Řezanková Analýza dat z dotazníkových šetření, Professional Publishing, Praha 2011.

18. S. L. Jackson, Research Methods and Statistics: A Critical Thinking Approach, Wadsworth Cengage Learning, Belmont 2012.

19. L. Marek, Statistika pro ekonomy: aplikace. 2. vyd. Praha: Professional Publishing, 2007.

20. R. G. Duffet, The Influence of Facebook Advertising on Cognitive Attitudes Amid Generation Y. Elecronic Commerce Research, 15, 243-267 (2015)

21. S. Giovannini, Y. Xu, J. Thomas, Luxury Fashion Consumption and Generation Y Consumers. Self, Brand Consciousness, and Consumption Motivations. Journal of Fashion Marketing and Management: An International Journal, 19, 22-40 (2015)

22. I. Boughzala, You: What Generation Y Thinks About Corporate Social Networking Applications? In: Proceedings of the $201447^{\text {th }}$ Hawaii International Conference on System Sciences, 6-9.01, IEEE, 688-696 (2014)

23. O. Ungerman, S. Myslivcová, Model of Communication Usable for Small and MediumSized Companies for the Consumer Communication in Social Media. E\&M Ekonomie a Management, 17, 167-184, (2014) 